\title{
PENGARUH MODEL PEMBELAJARAN PROJECT BASED LEARNING DENGAN PENDEKATAN STEM TERHADAP HASIL BELAJAR SISWA SMA
}

\author{
${ }^{1)}$ Teguh Wijayanto, ${ }^{1)}$ Bambang Supriadi, ${ }^{1)}$ Lailatul Nuraini \\ ${ }^{1)}$ Program Studi Pendidikan Fisika FKIP Universitas Jember \\ Email: teguhwijayanto32@gmail.com
}

\begin{abstract}
The learning model project based learning is an instructional model that can be applied to the STEM approach. Approach STEM (Science, Technology in, Engineering and Mathematic) is an approach that can be used in learning by using multiple disciplines. STEM approach in learning is very suitable to be applied in the curriculum in 2013 so that students are able to be more active, creative, and better understand the concepts taught in a material for a project which produced students in learning directly related to real-life experience of students in the everyday. The purpose of this study was to determine the influence of the learning model project based learning with STEM approach to the learning outcomes of high school students. The research was conducted in class X IPA 1 SMA Muhammadiyah 3 Jember, with 32 students at 15 male students and 17 female students. The method used in this research is the method pre-experiment design with one group pretestposttest design. Collecting data in this study using the initial test and final test. Student learning outcomes obtained after application project based learning model STEM learning approach shows $N$-gain category was at 0.62 .
\end{abstract}

Keywords: project based learning, approach STEM, learning outcomes.

\section{PENDAHULUAN}

Menurut Undang-undang Sisdiknas nomor 20 tahun 2003, pendidikan adalah suatu program yang dalam mewujudkan suasana belajar dan proses pembelajaran diperlukan adanya usaha sadar dan terencana agar siswa dapat aktif dalam mengembangkan potensi dirinya untuk memiliki kekuatan spiritual, pengendalian diri, kepribadian, kecerdasan, akhlak mulia, serta keterampilan yang diperlukan diri, masyarakat, bangsa, dan Negara. Dalam menciptakan kemampuan sumber daya manusia yang berkualitas perlu adanya suatu proses perkembangan dan kemajuan Ilmu Pengetahuan dan Teknologi (IPTEK). Salah satu ilmu pengetahuan yang berperan di bidang pendidikan dalam upaya peningkatan perkembangan kemajuan IPTEK adalah Ilmu Pengetahuan Alam (IPA). Menurut Trianto (2010) salah satu cabang ilmu dari IPA adalah fisika, dimana fisika adalah cabang ilmu sains yang memiliki langkah-langkah observasi, perumusan masalah, penyusunan hipotesis melalui elsperimen, penarikan kesimpulan, serta penemuan teori konsep.

Fisika adalah suatu ilmu sains yang di dalamnya mengajarkan tentang keteraturan pengkajian fenomena alam melalui pengetahuan, baik fakta, konsep, teori, serta prinsip melalui proses penemuan dan sikap ilmiah (Gunawan, 2015). Hal tersebut didukung oleh pendapat Sutarto (2010:131) yang mengatakan bahwa sains atau ilmu pengetahuan alam pada hakikatnya merupakan suatu ilmu yang 
memerlukan sebuah proses dan produk tentang pengkajian gejala alam dalam penerapannya. Maka dari itu untuk memahami konsep-konsep dalam fisika, siswa harus dapat membangun sendiri pengetahuan yang ada dalam benak siswa (pengalaman yang relevan), mencari, dan menemukan sendiri makna dari segala sesuatu yang dipelajari. Berdasarkan pendapat diatas dapat dikatakan bahwa fisika tidak hanya tentang menghafal rumus atau persamaan, namun dalam fisika harus ada suatu pemahaman konsep dasar yang diaplikasikan pada penyelesaian permasalahan dalam kehidupan seharihari yang sistematis. Namun dalam penerapannya masih banyak siswa yang merasa kesulitan dalam mempelajari ilmu fisika di sekolah.

Berdasarkan hasil wawancara yang dilakukan terhadap beberapa siswa di SMA Muhammadiyah 3 Jember didapatkan bahwa kebanyakan siswa belum mampu memahami konsep fisika secara dasar dalam pengaplikasian di kehidupan nyata, dan sering kebingungan tentang kegunaan mempelajari fisika karena hanya terpaku pada rumus matematis dan latihan soal yang diberikan guru. Apabila diberikan latihan soal model yang lain dengan mengganti variabel yang ditanyakan kebanyakan siswa merasa kebingungan dalam menjawab soal tersebut. Akibat dari seringnya siswa mendapatkan pembelajaran yang terpaku pada rumus, maka keaktifan dan kreativitas siswa cenderung terbatas dalam pengapilikasian fisika dalam kehidupan nyata terutama dalam perkembangan IPTEK. Maka dari itu perlu penerapan model pembelajaran yang melibatkan siswa agar aktif dan kreatif dalam pengaplikasian ilmu fisika dalam kehidupan nyata terutama dalam bidang IPTEK.

Model pembelajaran adalah sebuah perencanaan tutorial pembelajaran yang tersusun secara sistematis dan membentuk pola yang digunakan sebagai pedoman dalam merencanakan pembelajaran di kelas. Dengan demikian aktivitas pembelajaran benar-benar merupakan kegiatan bertujuan yang tertata secara sistematis. Hal ini berarti model pembelajaran memberikan kerangka dan arah bagi guru untuk mengajar (Trianto 2012:51). Project based learning adalah suatu model pembelajaran berbasis proyek yang mengkaitkan antara suatu permasalahan dengan kehidupan sehari-hari. Proyek yang dimaksud adalah suatu rancangan berupa ilmu pengetahuan, teknologi, masyarakat, sejarah, matematika, serta politik. Pada kurikulum 2013 salah satu model pembelajaran yang sangat disarankan untuk mencapai tingkat keaktifan dan kreatifitas siswa adalah model pembelajaran project based learning (Gulbahar \& Tinmaz, 2006). STEM adalah suatu pendekatan yang dapat digunakan dalam model pembelajaran project based learning. STEM projectbased learning sangat potensial untuk memberikan pembelajaran yang bermakna yang dapat melatih siswa untuk melakukan pemecahan masalah melalui sebuah proyek yang terintegrasi dengan satu atau beberapa bidang keilmuan lain seperti science, technologi, engineering dan mathematic. Science adalah kemampuan pengetahuan dalam memahami fenomena alam dalam kehidupan nyata. Technologi adalah kemampuan dalam mengenal, mengembangkan, menganalisis 
teknologi baru yang mempengaruhi kehidupan masyarakat. Engineering adalah kemampuan tentang pengembangan teknologi melalui proses desain rekayasa berupa proyek dalam pembelajaran. Mathematic adalah kemampuan dalam menganalisis, merumuskan, memecahkan masalah, dan menafsirkan solusi untuk masalah matematika dalam menerapkan berbagai situasi yang berbeda. Model pembelajaran project based learning berbasis STEM pada penelitian ini diharapkan dapat meningkatkan hasil belajar siswa SMA Muhammadiyah 3 Jember.

Hasil belajar adalah kemampuan yang dimiliki oleh siswa setelah mengikuti proses pembelajaran baik itu kognitif, afektif, dan psikomotor (Kunandar, 2013:63). Hal tersebut didukung dengan pendapat Arikunto (2013:32) bahwa menurut Bloom terdapat tiga ranah dalam hasil belajar yakni ranah kognitif, afektif, dan psikomotorik. Hasil belajar kognitif meliputi $\mathrm{C} 1$ (pengetahuan/ingatan), $\mathrm{C} 2$ (pemahaman), C3 (penerapan), C4 (analisis), C5 (sintesis), dan C6 (evaluasi).

Menurut Nurazizah (2018) menyatakan bahwa penerapan pembelajaran berbasis STEM dapat meningkatkan pencapaian hasil belajar siswa. Cahyaningsih (2018) menyatakan bahwa pembelajaran IPA berbasis STEM-PBL memberikan pengaruh terhadap hasil belajar kognitif peserta didik dengan effect size kategori sedang. Hasil penelitian Amatullah (2019) juga mengatakan bahwa terdapat pengaruh signifikan dari penerapan model pembelajaran inkuiri yang diterapkan dengan pendekatan STEM terhadap hasil belajar.

Beberapa peneliti menyebutkan bahwa model pembelajaran berbasis proyek dapat meningkatkan hasil belajar. Penelitian Mahanal et al. (2010) menyatakan bahwa siswa dengan model pembelajaran project based learning memiliki prestasi kognitif lebih tinggi dari siswa konvensional. Didukung oleh penelitian Jagantara et al. (2014) yang menyatakan bahwa terdapat perbedaan yang signifikan hasil belajar siswa yang menggunakan model pembelajaran berbasis proyek akan lebih aktif, kreatif dan inovatif dalam penyelesaian masalah dibandingkan dengan siswa yang menggunakan model pembelajaran secara langsung. Lutfi (2018) juga menyatakan bahwa terdapat pengaruh penerapan model pembelajaran project based learning terintegrasi STEM pada peningkatan literasi sains, kreativitas, dan hasil belajar siswa. Model ini sangat efektif diterapkan karena mendapatkan hasil belajar dan respon yang sangat positif dari siswa. Penelitian lain tentang integrasi STEM pada model pembelajaran project based learning yakni penelitian Furi et al. (2018) menyatakan bahwa nilai kreativitas dan peningkatan hasil belajar siswa menggunakan model pembelajaran project based learning dengan integrasi STEM memiliki nilai kreatifitas dan hasil belajar yang lebih tinggi dari pada model pembelajaran project based learning tanpa STEM. Maka dari itu penelitian ini mengulas tentang pengaruh model pembelajaran project based learning dengan pendekatan STEM terhadap hasil belajar siswa SMA. 


\section{METODE PENELITIAN}

Penelitian yaang digunakan adalah jenis penelitian pre-eksperiment dengan jenis one-group pretest-postest design. Dalam penelitian ini populasi dalam pengambilan sampel adalah siswa kelas $\mathrm{X}$ IPA di SMA Muhammadiyah 3 Jember pada tahun ajaran 2019/2020 pada materi fisika pokok bahasan vektor. Dengan menggunakan teknik purposive sampling, peneliti memilih sampel kelas X IPA 1. Penelitian ini menggunakan satu kelas eksperimen yang akan diberi perlakuan sesuai kriteria yang telah ditentukan oleh peneliti. Satu kelas eksperimen ini akan diberi soal pre-test sebelum dilakukan perlakuan yaitu dengan melaksanakan proses pembelajaran menggunakan model project based learning dengan pendekatan STEM. Setelah diberikan perlakuan, maka kelas eksperimen ini akan diberikan soal post-test untuk melihat peningkatan hasil belajar siswa.

Pada penelitian ini hasil belajar yang diukur adalah hasil belajar kognitif siswa dengan soal tes uraian. Peningkatan hasil belajar setelah melaksanakan pembelajaran dengan model project based learning dapat diketahui dengan kriteria skor $\mathrm{N}$-gain

$$
<\mathrm{g}>=\frac{\text { Spost-Spre }}{\text { Smax }- \text { Spre }}
$$

Dengan :

$\langle\mathrm{g}\rangle=$ Nilai gain

Spost $=$ Nilai Post-test

Spre = Nilai pre-test

Smax = Nilai Maksimal

Selanjutnya dari hasil perhitungan $N$ - gain tersebut kemudian dikonversi dengan kriteria sebagaimana ditunjukkan pada tabel 1 berikut:
Tabel 1. Kriteria Normalized Gain

\begin{tabular}{cc}
\hline Skor $N$-Gain & $\begin{array}{c}\text { Kriteria Normalized } \\
\text { Gain }\end{array}$ \\
\hline $0,70<N$-Gain & Tinggi \\
\hline $0,30 \leq N$-Gain $\leq 0,70$ & Sedang \\
\hline$N$-Gain $<0,30$ & Rendah \\
\hline
\end{tabular}

(Shilla et al., 2016)

Pengumpulan data dalam penelitian ini menggunakan teknik dokumentasi, observasi dan instrumen tes berupa soal uraian untuk mendeskripsikan peningkatan hasil belajar siswa setelah menggunakan model project based learning dengan pendekatan STEM kelas X IPA 1 di SMA Muhammadiyah 3 Jember .

Langkah-langkah penelitian yang dilakukan adalah sebagai berikut:

a. Observasi di kelas X IPA 1 Selama 1 kali pertemuan

b. Menentukan populasi dan sampel daerah penelitian;

c. Menyusun perangkat pembelajaran yang akan dilaksanakan

d. Memberikan soal pre-test.

e. Melaksanakan penelitian dengan melakukan pembelajaran menggunakan model project based learning dengan STEM

f. Memberikan soal post-test diakhir pembelajaran.

g. Mengolah data skor pre-test dan skor post-test siswa.

h. Membuat pembahasan terkait hasil data yang telah diolah

i. Membuat kesimpulan.

\section{HASIL DAN PEMBAHASAN}

Pembelajaran Hasil dan pembahasan pada penelitian ini didapatkan berdasarkan perlakuan pada kelas eksperimen yaitu pada pembelajaran fisika dengan menggunakan model pembelajaran 
project based learning dengan pendekatan STEM pada pokok bahasan vektor. Dalam pengambilan data sebagai pembahasan dilakukanlah sebuah tes untuk mengetahui peningkatan atau besar pengaruh dari perlakuan model yang dilakukan peneliti pada kelas eksperimen.

Penelitian ini dilaksanakan di SMA Muhammadiyah 3 Jember tepatnya pada bulan September 2019, diterapkan di kelas X IPA 1 menggunakan model pembelajaran project based learning dengan pendekatan STEM. Pada pembelajaran project based learning terdapat tahapan-tahapan dalam proses pembelajarannya. Tahapan pembelajaran project based learning berbasis STEM menurut (Laboy-Rush, 2010) adalah sebagai berikut.

1) Tahap Reflection

Pada tahap ini bertujuan untuk membawa siswa ke dalam konteks masalah dan memberikan inspirasi kepada siswa agar dapat segera mulai menyelidiki/investigasi. Fase ini juga dimaksudkan untuk menghubungkan apa yang diketahui dan apa yang perlu dipelajari.

2) Tahap Research

Pada tahap ini adalah bentuk penelitian siswa. Guru memberikan pembelajaran sains, memilih bacaan, atau metode lain untuk mengumpulkan sumber informasi yang relevan. Proses belajar lebih banyak terjadi selama tahap ini, kemajuan belajar siswa mengkonkritkan pemahaman abstrak dari masalah. Selama fase research, guru lebih sering membimbing diskusi untuk menentukan apakah siswa telah mengembangkan pemahaman konseptual dan relevan berdasarkan proyek.

3) Tahap Discovery

Tahap penemuan umumnya melibatkan proses menjembatani research dan informasi yang diketahui dalam penyusunan proyek. Ketika siswa mulai belajar mandiri dan menentukan apa yang masih belum diketahui. Beberapa model dari STEM PjBL membagi siswa menjadi kelompok kecil untuk menyajikan solusi yang mungkin untuk masalah, berkolaborasi, dan membangun kerjasama antar teman dalam kelompok. Model lainnya menggunakan langkah ini dalam mengembangkan kemampuan siswa dalam membangun habit of mind dari proses merancang untuk mendesain.

4) Tahap Application

Pada tahap aplikasi tujuannya untuk menguji produk/solusi dalam memecahkan masalah. Dalam beberapa kasus, siswa menguji produk yang dibuat dari ketentuan yang ditetapkan sebelumnya, hasil yang diperoleh digunakan untuk memperbaiki langkah sebelumnya. Di model lain, pada tahapan ini siswa belajar konteks yang lebih luas di luar STEM atau menghubungkan antara disiplin bidang STEM.

5) Tahap Communication

Tahap akhir dalam setiap proyek dalam membuat produk/solusi dengan mengkomunikasikan antar teman maupun lingkup kelas. Presentasi merupakan langkah penting dalam proses pembelajaran untuk mengembangkan keterampilan komunikasi dan kolaborasi maupun kemampuan 
untuk menerima dan menerapkan 13 umpan balik yang konstruktif. Seringkali penilaian dilakukan berdasarkan penyelesaian langkah akhir dari fase ini.

Kelima tahapan model pembelajaran project based learning dengan pendekatan STEM dilakukan untuk mengetahui besar peningkatan hasil belajar siswa SMA Muhammadiyah 3 Jember. Pengambilan data dilakukan sebagai sarana mengetahui peningkatan hasil belajar siswa dengan melakukan pretest dan post-test. Data hasil nilai pretest dan nilai post-test pada kelas eksperimen sebagaimana ditunjukkan pada tabel 2 berikut.

Tabel 2. Hasil pre-test dan post-test

\begin{tabular}{lcc}
\hline & Pre-test & Post-test \\
\hline Nilai rata-rata & 55,8 & 79,4 \\
\hline Nilai tertinggi & 87 & 94 \\
\hline Nilai terendah & 34 & 75 \\
\hline
\end{tabular}

Data hasil belajar siswa diperoleh melalui kegiatan pre-test diawal penelitian sebelum diberikan perlakuan model, selanjutnya diberikan post-test diakhir penelitian. Data yang diperoleh dianalisis menggunakan kriteria skor $N$-gain. Adapun kriteria peningkatan hasil belajar menggunakan skor $\mathrm{N}$-gain dilihat pada Tabel 3 .

Tabel 3. Kriteria Skor N-gain

\begin{tabular}{ccc}
\hline Kelas & $N$-gain & Kriteria \\
\hline Kelas Eksperimen & 0,62 & Sedang \\
\hline
\end{tabular}

Pada Tabel 3. menunjukkan peningkatan hasil belajar siswa tergolong sedang. Hasil ini didapatkan karena dalam pelaksanaan pembelajaran dengan model projectbased learning dengan pendekatan STEM siswa didorong dapat lebih aktif dan dapat lebih memahami konsep materi yang diberi;kan. Pemahaman ini didapatkan melalui kegiatan proyek dalam pembelajaran. Pada proses pelaksanaan model project based learning terintegrasi STEM dalam pembelajaran membutuhkan kreatifitas siswa dalam bekerjasama dalam mencari solusi suatu permasalahan. Pelaksanaan model project based learnig dengan pendekatan STEM pada kelas $X$ IPA 1 di SMA Muhammadiyah 3 Jember dapat membuat suasana belajar siswa dikelas lebih menarik dengan melibatkan siswa secara langsung dalam proses perancangan proyek dalam pemecahan masalah. Sehingga siswa lebih tertarik dalam belajar dan lebih mudah memahami materi pembelajaran. Oleh sebab itu, pelaksanaan model project based learnig dengan pendekatan STEM dapat meningkatkan hasil belajar siswa dengan kategori $\mathrm{N}$-gain sedang sebesar 0,62.

Peningkatan hasil belajar tersebut sesuai dengan penelitian Damayanti \& Surindra (2018) menyatakan bahwa penerapan model pembelajaran berbasis proyek pada mata kuliah kewirausahaan terdapat perbedaan yang signifikan dalam hasil belajar dibandingkan dengan pembelajaran biasa. Menurut penelitian Yance (2013) menyatakan bahwa penerapan model pembelajaran project based learning berpengaruh besar terhadap hasil belajar siswa baik dari aspek kognitif, afektif, dan psikomotor. Hal tersebut juga didukung oleh hasil penelitian Laboy-Rush (2010) yang menyatakan bahwa penerapan model pembelajaran berbasis STEM dapat meningkatkan hasil belajar siswa. Bukan hanya hasil belajar siswa, 
kreatifitas siswa dalam pembelajaran juga dapat meningkat.

\section{SIMPULAN DAN SARAN}

Pengaruh pelaksanaan pembelajaran fisika menggunakan model project based learnig dengan pendekatan STEM pada pokok bahasan vektor di kelas X IPA 1, SMA 3 Muhammadiyah 3 Jember terhadap peningkatan hasil belajar siswa tergolong sedang. Sehingga dapat disimpulkan bahwa penelitian model project based learning dengan pendekatan STEM dapat meningkatkan hasil belajar siswa. Siswa lebih memahami konsep materi yang diberikan karena siswa dapat terlibat aktif secara langsung dalam penyusunan perancangan proyek dalam pemecahan masalah menggunakan konsep fisika.

Adapun saran dalam penelitian ini yaitu diharapkan dapat dijadikan landasan untuk penelitian yang lebih lanjut. Selain itu, dapat dijadikan guru sebagai referensi dalam menggunakan model pembelajaran berbasis STEM dalam upaya meningkatkan hasil belajar siswa.

\section{DAFTAR PUSTAKA}

Amatullah, S. F., I. W. Distrik, dan I. Wahyudi. 2019. Pengaruh Model Pembelajaran Inkuiri Terbimbing Berbantuan Buku Siswa Berbasis Pendekatan Terpadu STEM Terhadap Hasil Belajar. Jurnal Pendidikan Fisika. 7(1).

Arikunto, S. 2013. Dasar-dasar Evaluasi Pendidikan Edisi 2. Jakarta: Bumi Aksara.
Cahyaningsih, F., dan E. Roektiningroem. 2018. Pengaruh Pembelajaran IPA Berbasis STEM-PBL Terhadap Keterampilan Berpikir Kritis dan Hasil Belajar Kognitif. 7(5).

Damayanti, S., dan B. Surindra. 2018. Penerapan Model Pembelajaran Project Based Learning pada Mata Kuliah Kewirausahan dalam Meningkatkan Hasil Belajar Mahasiswa. 3(2).

Furi, I. M. L., S. Handayani, S. Maharani. 2018. Eksperimen Model Pembelajaran Project Based Learning dan Project Based Learning Terintegrasi STEM untuk Meningkatkan Hasil Belajar dan Kreativitas Siswa Pada Kompetensi Dasar Teknologi Pengolahan Susu. Jurnal Penelitian Pendidikan. 35 .

Gulbahar, Y., \& Tinmaz, H. 2006. Implementing Project-Based Learning and E-Portofolio Assesment In an Undergraduate Course. Journal of Research on Technology in Education, 38 (3): 309-327.

Gunawan. 2015. Model Pembelajaran Sains Berbasis ICT. Mataram: FKIP UNRAM.

Jagantara, I. M. W., P. B. Adnyana, dan N. L. P. M. Widiyanti. 2014. Pengaruh Model Pembelajaran Berbasis Proyek (Project Based Learning) Terhadap Hasil Belajar Biologi Ditinjau dari Gaya Belajar 
Siswa SMA. Jurnal Pendidikan dan Pembelajaran IPA Indonesia. 4(1).

Kunandar. 2013. Penilaian Autentik. Jakarta: Rajawali Pers.

Lutfi, A. A. Aziz, dan Ismail. 2018. Pengaruh Project Based Learning Terintegrasi STEM Terhadap Literasi Sains, Kreativitas dan Hasil Belajar Peserta Didik. Prosiding Seminar Nasional Biologi dan Pembelajarannya.

Mahanal, S., E. Darmawan, A. D. Corebima, dan S. Zubaidah. 2010. Pengaruh Pembelajaran Project Based Learning (PjBL) pada Materi Ekosistem terhadap Sikap dan Hasil Belajar Siswa SMAN 2 Malang. Jurnal Pendidikan Biologi. 1(1).

Nurazizah, I. R. Suwarma, dan A. Jauhari. 2018. Implementasi Pembelajaran Stem: Kajian Terhadap Pencapaian Hasil Belajar Siswa. Prosiding Seminar Nasional Fisika. 4(1).

Shilla, R. A., Sutarto, dan A. Harijanto. 2016. Model Pembelajaran instruction, doing, dan evaluating (MPIDE) dengan video kejadian fisika dalam pembelajaran fisika di SMA. Jurnal Pembelajaran Fisika. Vol.4(4): 344-349.
Sutarto. 2010. Model Pembelajaran dengan Aktivitas Lapangan dan Laboratorium (MPALL) untuk Pembelajaran di SD. Jurnal Pendidikan MIPA dan MIPA. Saintifika 12(2), 131-160.

Trianto. 2010. Model Pembelajaran Terpadu. Jakarta: Bumi Aksara.

Trianto. 2012. Model Pembelajaran Terpadu. Jakarta: PT Bumi Aksara.

Laboy-Rush, D. 2010. Integrated STEM education through project-based learning. www.learning.com/stem/whitep aper/ integrated-STEM-through Project-based-Learning.

Yance, R. D. 2013. Pengaruh Penerapan Model Project Based Learning (PBL) Terhadap Hasil Belajar Fisika Siswa Kelas XI IPA SMA Negeri 1 Batipuh Kabupaten Tanah Datar. Jurnal Berkala Ilmiah Pendidikan Fisika. 1. 